\title{
Spatial and temporal analysis of drought in Manjalar sub-basin of Vaigai in Tamil Nadu using standardized precipitation index
}

\author{
S. Janapriya ${ }^{*}$, S. Santhana Bosu ${ }^{2}$, Balaji Kannan ${ }^{3}$ and S. Kokilavani ${ }^{4}$ \\ ${ }^{1}$ Soil and Water Conservation Engineering, Vanavarayar Institute of Agriculture, Manakkadavu, Pollachi-642103 \\ (Tamil Nadu), INDIA \\ ${ }^{2 \& 3}$ Soil and Water Conservation Engineering, Tamil Nadu Agricultural University, Coimbatore -641003 (Tamil \\ Nadu), INDIA \\ ${ }^{4}$ Agricultural Meteorology, Tamil Nadu Agricultural University, Coimbatore -641003 (Tamil Nadu), INDIA \\ *Corresponding author. E-mail: jans.priya@gmail.com \\ Received: August 20, 2015; Revised received: January 11, 2016; Accepted: April 14, 2016
}

\begin{abstract}
Drought is universally acknowledged as a phenomenon associated with scarcity of water. Drought characterization is essential for drought management operations. Using drought indices is a pragmatic way to assimilate large amounts of data into quantitative information that can be used in applications such as drought forecasting, declaring drought levels, contingency planning and impact assessment. Using monthly mean precipitation data for a period of 1982-2012 from 12 raingauge stations in the Manjalar sub-basin of Vaigai using Standardized Precipitation Index (SPI) is produced for the drought analysis with the time scale of 3 months (SPI-3), 6 months (SPI-6) and 12 months (SPI-12) as they are applicable for agriculture and hydrological aspects, respectively. It was observed that the basin experienced frequent droughts for all months of the year. The highest percentage of occurrence of drought was observed in the month of July (15.3), May (15.4) and August (15.6) at SPI-3, SPI-6 and SPI-12 respectively. On an average we observed 32.6, 8.6, 5.6 and 2.3 percentages of drought occurred by mild, moderate, severe and extreme drought respectively with respect to SPI-12. The results showed that mild droughts occur most frequently and extreme droughts occur least frequently and the basin suffered severe drought during the year of 1985, 2004 and 2006. The central and south eastern parts of the basin had more potential sensitivity to the droughts in comparison with the other areas of the basin
\end{abstract}

Keywords: Drought, Spatial and temporal analysis, SPI index

\section{INTRODUCTION}

Drought is a natural disaster which causes the greatest loss in the world and has the largest impacts among all the natural disasters. Drought has significant impact on socio-economic, agricultural, and environmental aspects (Bhuiyan, 2004). The success of drought preparedness and mitigation depends, to a large extent, upon timely information on drought onset, progress and areal extent. Drought monitoring is normally performed using drought indices. In general, drought indices is a function of several hydro metrological variables (e.g., rainfall, temperature, stream flow, soil moisture, etc.) and assess the different types of drought i.e. meteorological (precipitation), hydrological (stream flow), agricultural (soil moisture) drought. In this study, drought was considered as a meteorological phenomenon characterized by prolonged periods of abnormal rainfall deficit. Drought is a frequent phenomenon in India and drought areas are mainly confined to the Peninsular and Western parts of the country and there are only few pockets in the central, eastern, northern and southern parts. Out of 329 Million ha of total geographical area in India about 107 Million ha of lands are subjected to different degrees of water stress and drought conditions (Mishra and Desai, 2005). More than 100 districts spread over 13 states of India have been identified as drought prone districts, out of these, about 8 districts falls in the Tamil Nadu (Gupta et al., 2011). The southern regions of Tamil Nadu (Theni, Dindigul and Madurai districts) have suffered with severe droughts at many times in the past. Due to the growth of population and expansion of agricultural, energy and industrial sectors, the demand for water has increased manifold and even water scarcity has been occurring almost every year. Other factors, such as climate change and contamination of water supplies, have further contributed to the water scarcity. In recent years, droughts have been experienced with higher peaks and severity levels. Assessment of droughts is of primary importance for water resources planning and management. This requires understanding historical droughts in the region as well as different concepts of droughts that will be helpful to investigate different drought properties.

Many drought indices have been developed to date. 
Table 1. Drought classification by SPI value and corresponding probabilities.

\begin{tabular}{lccc}
\hline S.N. & \multicolumn{2}{c}{ Drought Category } & SPI value \\
\hline 1 & D1 & Mild drought & 0 to -0.99 \\
2 & D2 & Moderate drought & -1.00 to -1.49 \\
3 & D3 & Severe drought & -1.50 to -1.99 \\
4 & D4 & Extreme drought & $\leq-2.00$ \\
\hline
\end{tabular}

These include the Palmer Drought Severity Index (PDSI - Palmer, 1965), which is widely used in the United States, the decile index (Gibbs and Maher, 1967), which is operational in Australia, the China- $Z$ index (CZI), which is used by the National Metrological Center of China (Wu et al., 2001), the Surface Water Supply Index (SWSI - Shafer and Dezman, 1982) adopted by several states in the United States, and standardized precipitation index (SPI - McKee et al., 1993), which has gained world popularity, etc.

The present study was carried out in the Manjalar subbasin of Vaigai basin spread over drought prone districts of Theni, Dindigul and Madurai districts of Tamil Nadu. The aims of this research are to investigate the temporal variation and spatial distribution of drought characteristics in the Manjalar sub-basin of Vaigai basin and to compare the performance and evaluate the applicability of several rainfall-based drought indices.

\section{MATERIALS AND METHODS}

Study area and data used: The Vaigai river basin forms one of the important river basins of Southern Tamil Nadu with its fertile, lush green paddy fields and well developed irrigation system. Next to Cauvery river basin, this basin can be considered as the granary of Southern Tamil Nadu. Manjalar is one of the sub basin of Vaigai river basins in Tamil Nadu. Manjalar sub-basin (Fig. 1) is grouped into 4 sub basins such as Varattar Nagalar, Varahanadhi, Manjalar and Sirumalaiar sub basin and spread over an area of $2166 \mathrm{~km}^{2}$. $40 \%$ of the basin area $\left(873.3 \mathrm{~km}^{2}\right)$ is covered with hills and dense forest cover. This basin is bounded in north and east by Cauvery basin, south and west by Kerala

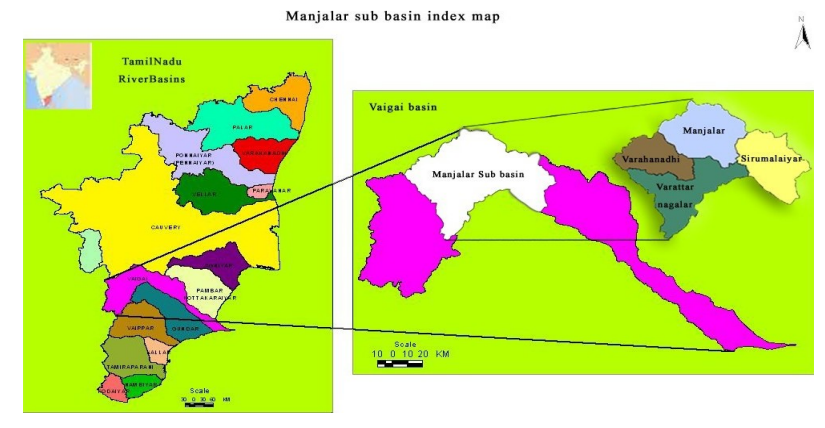

Fig. 1. Location of study area.

State. This basin area lies within the coordinates of North latitude between - $9^{\circ} 50^{\prime} 00^{\prime \prime}$ to $10^{\circ} 20^{\prime} 00^{\prime \prime}$ and East longitudes $77^{\circ} 20^{\prime} 00^{\prime \prime}-78^{\circ} 10^{\prime} 00^{\prime \prime}$. Manjalar sub basin has an undulating topography with maximum contour elevation in the Hill is $2410 \mathrm{~m}$ and the minimum spot height in the plain is $143 \mathrm{~m}$ above MSL. The average annual rainfall in the Manjalar sub-basin has a large geographic variation. More rainfall can be observed in the Northern west parts of the basin, when it comes to the central and southwestern parts of the basin, the rainfall decreases. Mean annual rainfall over the whole PAP basin is about $876.9 \mathrm{~mm}$ and it is distributed unevenly in space and time. The mean annual precipitation varies from about $600 \mathrm{~mm}$ at the central and south western plain area to more than $1590.3 \mathrm{~mm}$ at the North western mountain areas. Generally, rainfall is rare from January to May (winter and summer season). The prolonged and significant decrease on monthly and annual rainfall resulted in irrigation cutbacks, over exploitation of groundwater and significant losses of crop yields.

The monthly rainfall data for the period of 30 years (1982-2012) from 13 rain gauge stations located in the Manjalar sub basin was collected from the office of Groundwater division, Public Works Department, Taramani, Chennai. The methodology comprised of rainfall using spatial interpolation technique, development of mean monthly areal rainfall at 3,6 and 12-month time scale and calculation of regional representative of

Table 2. Monthly Occurrence of drought at 3,6 and 12 month time scale.

\begin{tabular}{|c|c|c|c|c|c|c|c|c|c|c|c|c|c|c|c|}
\hline \multirow{2}{*}{ Month } & \multicolumn{5}{|l|}{ SPI_3 } & \multicolumn{5}{|l|}{ SPI_6 } & \multicolumn{5}{|c|}{ SPI_12 } \\
\hline & D1 & D2 & D3 & D4 & Total & D1 & D2 & D3 & D4 & Total & D1 & D2 & D3 & D4 & Total \\
\hline January & 9.8 & 1.83 & 0.83 & 1 & 13.5 & 9.2 & 2.25 & 1.67 & 0.67 & 13.8 & 9.8 & 2.50 & 1.42 & 1.00 & 14.8 \\
\hline February & 9.8 & 2.17 & 0.92 & 1.5 & 14.4 & 9.4 & 2.50 & 1.00 & 0.83 & 13.8 & 9.7 & 2.25 & 1.58 & 1.00 & 14.5 \\
\hline March & 8.6 & 1.33 & 0.67 & 3.75 & 14.3 & 9.6 & 1.83 & 1.33 & 0.92 & 13.7 & 9.3 & 2.67 & 1.83 & 0.58 & 14.4 \\
\hline April & 10.8 & 1.25 & 1.00 & 1.25 & 14.3 & 10.7 & 2.33 & 1.33 & 0.67 & 15.0 & 8.8 & 3.17 & 1.42 & 0.75 & 14.1 \\
\hline May & 10.7 & 1.58 & 1.42 & 0.83 & 14.5 & 10.4 & 3.42 & 1.17 & 0.42 & 15.4 & 9.4 & 2.58 & 2.08 & 0.50 & 14.6 \\
\hline June & 10.2 & 2.00 & 0.83 & 1.17 & 14.2 & 9.8 & 2.33 & 0.92 & 0.92 & 14.0 & 9.1 & 2.50 & 2.08 & 0.58 & 14.3 \\
\hline July & 10.8 & 2.08 & 1.50 & 0.83 & 15.3 & 9.7 & 2.33 & 1.17 & 0.83 & 14.0 & 8.9 & 2.58 & 2.17 & 0.58 & 14.3 \\
\hline August & 9.5 & 2.33 & 1.08 & 0.83 & 13.8 & 10.8 & 2.08 & 1.25 & 0.75 & 14.8 & 11.0 & 2.33 & 1.75 & 0.50 & 15.6 \\
\hline September & 8.5 & 2.58 & 0.67 & 1 & 12.8 & 11.3 & 2.17 & 1.00 & 0.92 & 15.3 & 10.3 & 2.92 & 1.50 & 0.50 & 15.3 \\
\hline October & 8.5 & 2.58 & 0.67 & 1 & 12.8 & 9.5 & 2.17 & 1.42 & 1.00 & 14.1 & 10.1 & 2.58 & 1.58 & 0.83 & 15.1 \\
\hline November & 10.3 & 2.33 & 0.75 & 1 & 14.3 & 9.4 & 2.17 & 1.17 & 1.08 & 13.8 & 10.6 & 2.17 & 1.42 & 0.75 & 14.9 \\
\hline December & 9.3 & 1.67 & 1.33 & 1 & 13.3 & 9.6 & 2.50 & 1.42 & 0.67 & 14.2 & 10.2 & 2.58 & 1.17 & 0.83 & 14.8 \\
\hline $\begin{array}{l}\text { Total } \\
\% \text { of Oc- }\end{array}$ & 116.8 & 23.8 & 11.7 & 15.2 & 167.3 & 119.3 & 28.1 & 14.8 & 9.7 & 171.8 & 117.2 & 30.8 & 20.0 & 8.4 & 176.4 \\
\hline currence & 69.77 & 14.19 & 6.97 & 9.06 & 100.0 & 69.4 & 16.34 & 8.63 & 5.63 & 100 & 66.41 & 17.48 & 11.34 & 4.77 & 100 \\
\hline
\end{tabular}


Table 3. Lowest SPI value for 12 stations during 1982-2012.

\begin{tabular}{|c|c|c|c|c|c|c|c|c|c|}
\hline \multirow{2}{*}{$\begin{array}{l}\text { Station Number } \\
\text { and Name/ SPI } \\
\text { Values }\end{array}$} & \multicolumn{3}{|c|}{ SPI_3 } & \multicolumn{3}{|c|}{ SPI_6 } & \multicolumn{3}{|c|}{ SPI_12 } \\
\hline & Year & Month & $\begin{array}{c}\text { SPI } \\
\text { Value }\end{array}$ & Year & Month & $\begin{array}{c}\text { SPI } \\
\text { Value }\end{array}$ & Year & Month & $\begin{array}{c}\text { SPI } \\
\text { Value }\end{array}$ \\
\hline 1. Andipatti & 1988 & December & -3.33 & 1989 & February & -2.63 & 2004 & January & -2.18 \\
\hline 2.Bodinayakanur & 2006 & September & -3.96 & 2007 & November & -2.88 & 2007 & November & -2.82 \\
\hline 3.Cholavandan & 1997 & August & -3.78 & 2004 & April & -3.67 & 2004 & August & -3.33 \\
\hline 4.Madurai, PWD & 2006 & July & -3.00 & 1989 & April & -2.71 & 1983 & January & -2.59 \\
\hline 5.Manjalardam & 2009 & November & -3.29 & 2010 & February & -2.98 & 1998 & June & -2.25 \\
\hline 6.Nilakottai & 2003 & November & -3.50 & 2004 & February & -3.69 & 2004 & August & -2.72 \\
\hline 7.Perani & 2003 & November & -3.45 & 2004 & February & -3.67 & 2004 & June & -3.39 \\
\hline 8.Periyakulam & 2010 & June & -3.01 & 2010 & June & -3.03 & 1987 & February & -2.34 \\
\hline 9.Vaigaidam & 1985 & June & -3.73 & 1985 & July & -4.04 & 1986 & January & -2.85 \\
\hline 10.Veerapandi & 2001 & $\begin{array}{l}\text { December } \\
\text { March }\end{array}$ & -2.66 & 2002 & January & -2.84 & 2002 & February & -2.38 \\
\hline $\begin{array}{l}\text { 11.Viralipatti } \\
\text { 12.HRS, }\end{array}$ & $1983 \& 1992$ & $\begin{array}{c}\text { \&April } \\
\text { September }\end{array}$ & -2.52 & 1985 & July & -2.25 & 2012 & December & -2.04 \\
\hline Kodaikanal & 1998 & \& October & -2.62 & 1999 & July & -2.32 & 2000 & August & -2.14 \\
\hline
\end{tabular}

SPI values using mean areal rainfall for temporal drought analysis. The collected data has been processed and analyzed by preparing various charts, maps and diagrams using GIS software by using Inverse Distance Weighting (IDW) approach.

Use of the Standardized Precipitation Index (SPI) for drought analysis: The Standardized Precipitation Index (SPI) as a drought monitoring tool was designed at Colorado State University, U.S. to quantify the rainfall deficit on multiple time scales, and has been used to monitor drought conditions (McKee et al., 1993). A drought event occurs at the time when the value of SPI is continuously negative and the event ends when the SPI becomes positive. The main advantage of the SPI, in comparison with other indices, is that the SPI enables both determination of drought conditions at different time scales and monitoring of different drought types. This versatility allows the SPI to monitor shortterm water supplies, such as soil moisture, important for agricultural production, and longer-term water resources such as groundwater supplies, stream flow, and lake and reservoir levels. Numerous studies have been conducted to analysis the meteorological droughts using SPI (Hughes and Saunders, 2002; Mishra and Desai, 2005; Edossa et al., 2010; Moradi et al., 2011; Pradhan et al., 2011). Drought intensity classification into various categories with different values of SPI is given in the following Table1. Positive SPI values indicate greater than median precipitation and negative values indicate less than median precipitation. Selection of time scale: Szalai et al. (2000) assessed the utility of the SPI for describing drought in Hungary. They concluded that the SPI was suitable for quantifying most types of drought event. Stream flow was described best by SPIs with time scales of 2-6 months. Strong relationships to ground water level were found at time scales of 5-24 months. Agricultural drought (proxied by soil moisture content) was replicated best by the SPI on a scale of 2-3 months. Based on the above study this research uses at 3, 6 and 12 month time scale for agricultural and hydrological aspects. In the present study, running series of total precipitation corresponding to 3-months, 6-months and 12 -months were used and as result the corresponding SPIs were calculated: SPI_3, SPI 6 and SPI_12. SPI at different time scales, e.g. 1- or 3-month SPI of a particular month represents deviation in precipitation totals for the same month and current plus previous two months, respectively. Positive values indicate greater than mean precipitation and negative values indicate less than mean precipitation.

Calculation of SPI: The SPI for any location is calculated, based on the long-term rainfall record for a desired period. This is performed separately for each month and for each grid in space. The long-term record is fitted to a probability distribution, which is then transformed to a normal distribution so that the mean SPI for the location is zero and standard deviation of unity (McKee et al., 1993).

The gamma distribution is defined by its probability density function is

$$
g(x)=\frac{1}{\beta^{\alpha} \Gamma(\alpha)} x^{\alpha-1} e^{-x / \beta}
$$

$$
\text { for } x>0
$$

Where $\alpha>0$ is a shape factor, $\beta>0$ is a scale factor, and $\mathrm{x}>0$ is the amount of precipitation.

$\Gamma(\alpha)$ is the gamma function which is defined as

Table 4. Percentage of drought occurrence in Manjalar sub-basin (1982-2012).

\begin{tabular}{lcccc}
\hline \multirow{2}{*}{ SPI Classes } & \multirow{2}{*}{ Drought category } & \multicolumn{3}{c}{ Drought occurrences (\%) } \\
\cline { 3 - 5 } & Extreme & 3 month & 6 month & 12 month \\
\hline$\leq-2.00$ & Severe & 4.21 & 2.69 & 2.34 \\
-1.50 to -1.99 & Moderate & 3.24 & 4.12 & 5.56 \\
-1.00 to -1.49 & Mild & 6.6 & 7.80 & 8.56 \\
0 to -0.99 & 32.43 & 33.13 & 32.55 \\
\hline
\end{tabular}




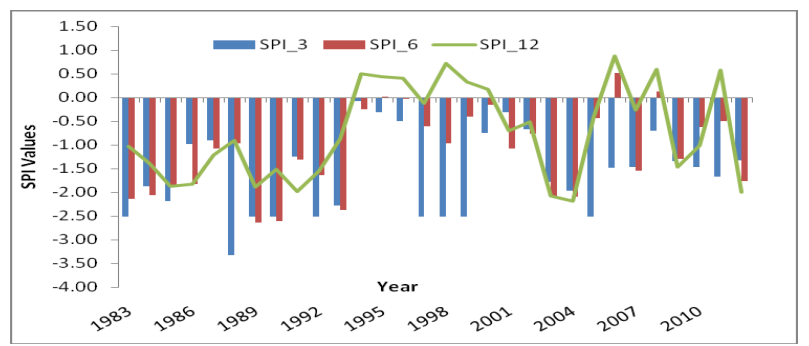

Station: Andipatti

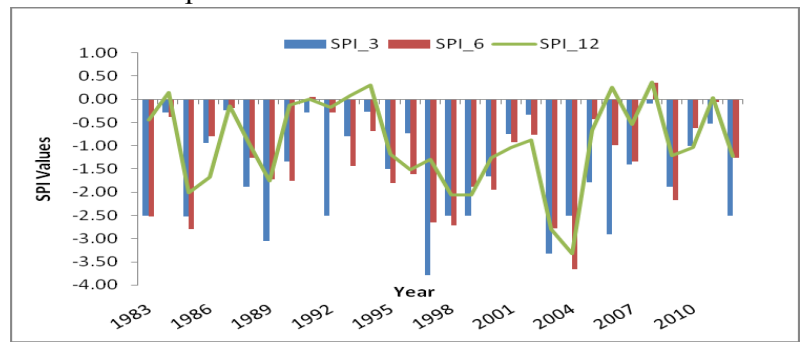

Station: Chlovandhan

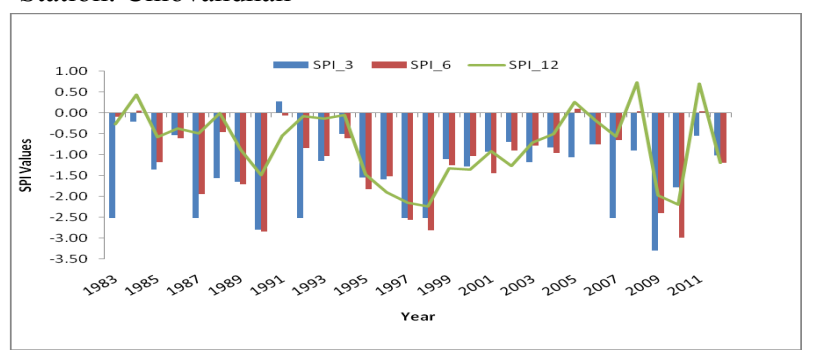

Station: Manjalar dam

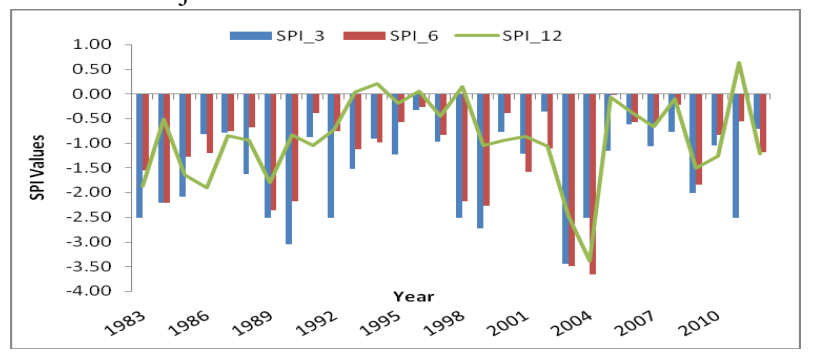

Station: Peranai

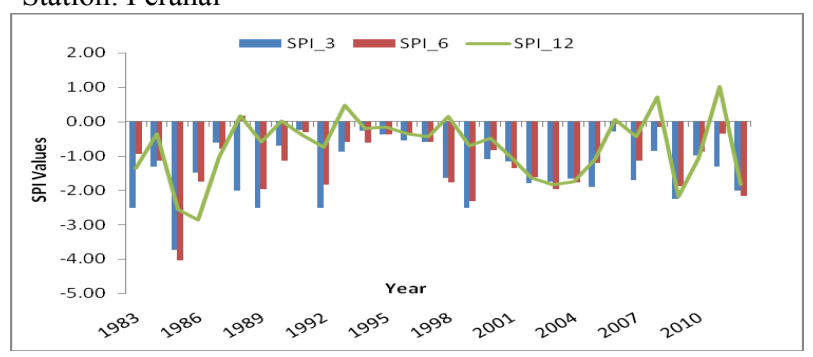

Station: Vaigai dam

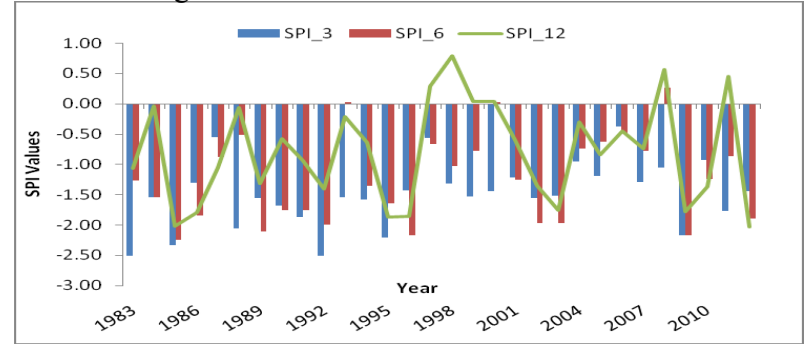

Station: Viralipatti

Fig. 2. Variation of SPI values at 3,6 and 12 month time scale for different raingauge station.

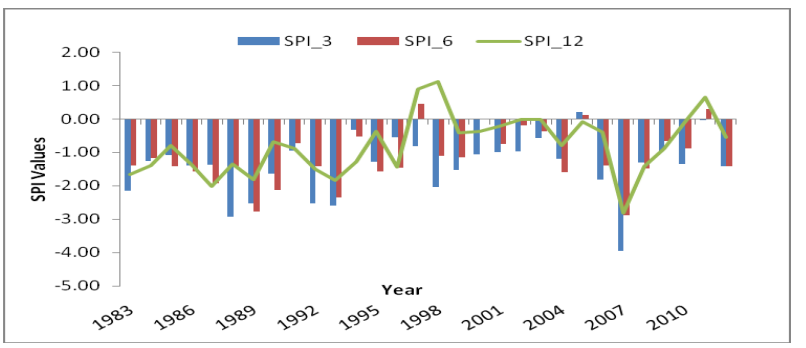

Station: Bodinayakanur

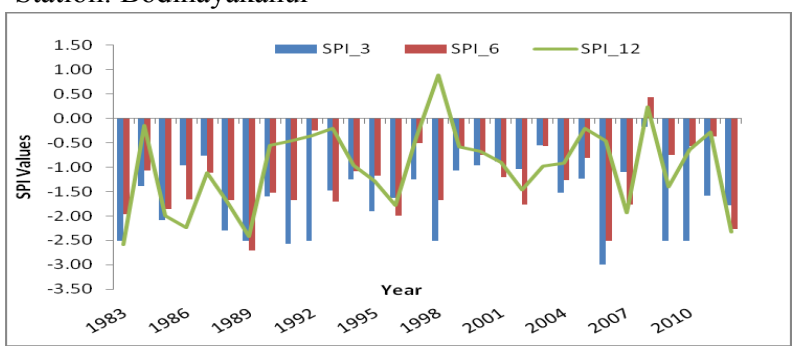

\section{Station: PWD, Madurai}

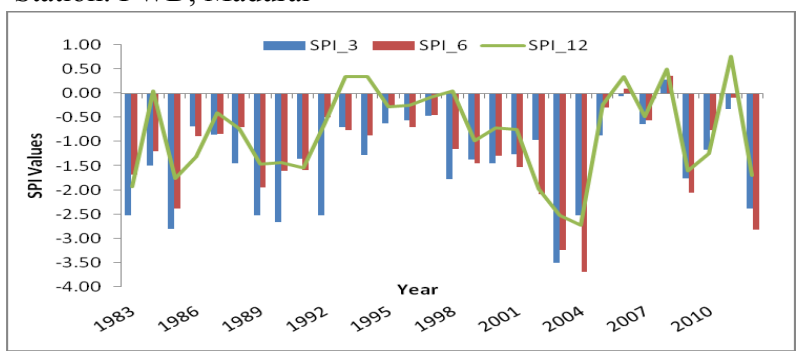

\section{Station: Nilakottai}

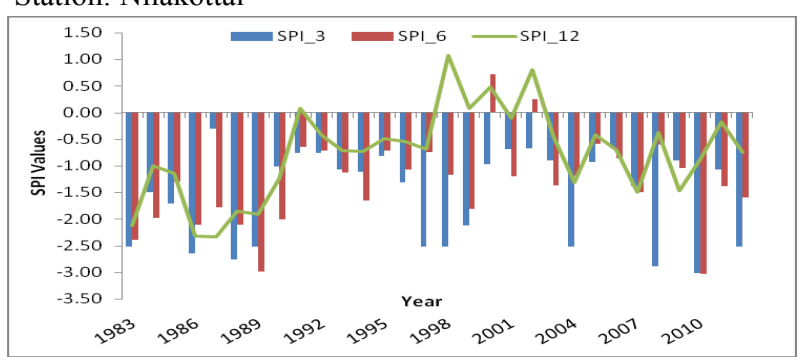

\section{Station: Periyakulam}

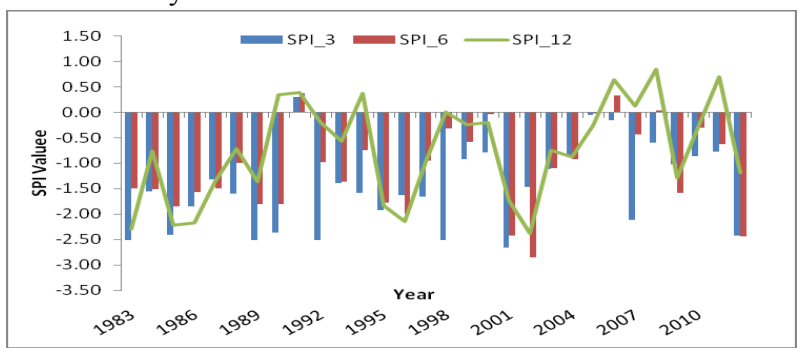

Station: Veerapandi

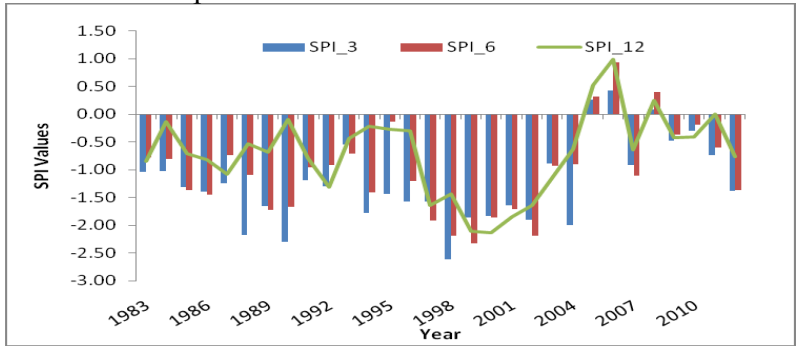

Station: HRS, Kodaikanal 

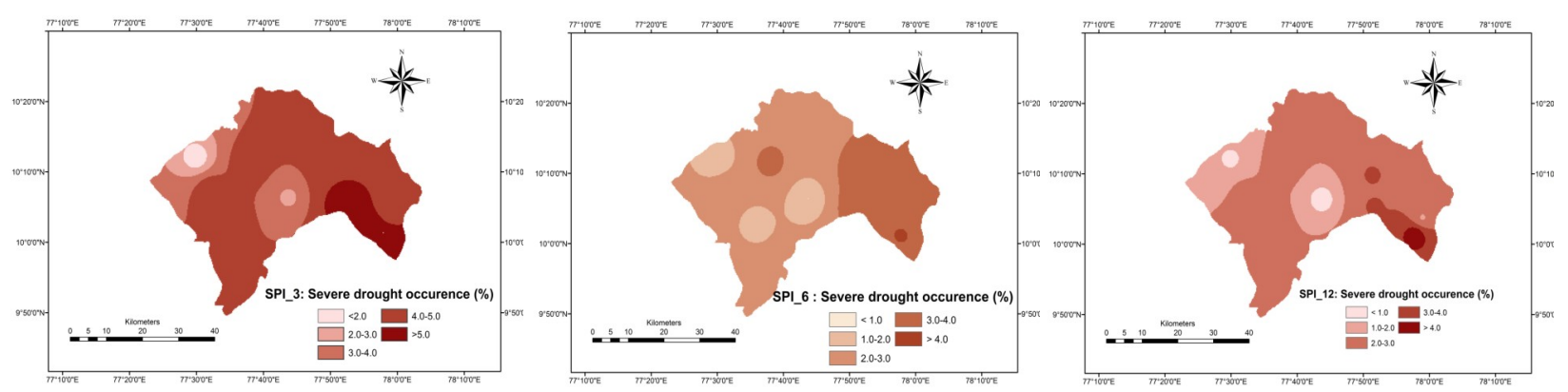

Fig 3. Occurrence of severe drought for 3,6 and 12 month time scale.

$$
\Gamma(\alpha)=\int_{0}^{-} y^{\alpha-1} e^{-y} d y
$$

Fitting the distribution to the data requires that $\alpha$ and $\beta$ be estimated. Edwards and McKee (1997) suggested a method for estimating these parameters using the maximum likelihood approximations of Thom (1958) as follows:

$$
\begin{aligned}
& \widehat{\alpha}=\frac{1}{4 \mathrm{~A}}\left(1+\sqrt{1+\frac{4 \mathrm{~A}}{3}}\right) \\
& \widehat{\beta}=\frac{\bar{x}}{\widehat{\alpha}}
\end{aligned}
$$

$---(5)$

Where,

$$
A=\ln (\bar{x})-\frac{\sum_{i=1}^{M} \ln (x)}{n}
$$

for $\mathrm{n}$ observations.

The resulting parameters are then used to find the cumulative probability of an observed rainfall event for the given month or any other time scale.

$$
\mathrm{G}(\mathrm{x})=\int_{0}^{\mathrm{x}} \mathrm{g}(\mathrm{x}) \mathrm{dx}=\frac{1}{\widehat{\beta^{\alpha} \Gamma(\hat{\alpha})}} \int_{0}^{x} \mathrm{x}^{\hat{\alpha}-1} \mathrm{e}^{-\mathrm{x} / \tilde{\beta}} \mathrm{dx}
$$

Substituting $t$ for ${ }^{x / \widehat{\beta}}$ reduces the above equation to incomplete gamma function:

$$
G(x)=\frac{1}{r(\hat{\alpha})} \int_{0}^{x} t^{\widehat{\alpha}-1} e^{-1} d t
$$

Since the gamma function is undefined for $\mathrm{x}=0$ and $\mathrm{a}$ precipitation distribution may contain zeros, the cumulative probability becomes:

$$
\mathrm{H}(\mathrm{x})=\mathrm{q}+(1-\mathrm{q}) \mathrm{G}(\mathrm{x})
$$

Where, $\mathrm{q}$ is the probability of zero precipitation. If $\mathrm{m}$ is the number of zeros in a rainfall time series, $q$ can be estimated by $\mathrm{m} / \mathrm{n}$. In this analysis, a small amount of rainfall was substituted for zero rainfall for each grid. This substitution does not affect the distribution of precipitation. For larger time scales (like 1, 3-, 6-, 9-, $12-$, 24-, 48-months) the probability of monthly null precipitation is zero. So the errors in calculating the parameters $\alpha$ and $\beta$ due to the monthly null precipita- tion does not affect the distribution at larger time scales.

The cumulative probability, $\mathrm{H}(\mathrm{x})$, is then transformed to the standard normal random variable $\mathrm{Z}$ with a mean of zero and a variance of one, which is the value of SPI. Following Edwards and McKee (1997) and Hughes and Saunders (2002), an approximate conversion is employed in this study.

For lower range of cumulative probability (i.e., $0<\mathrm{H}(\mathrm{x})$ $\leq 0.5)$

$$
\mathrm{Z}=\mathrm{SPI}=-\left(\mathrm{t}-\frac{\mathrm{c}_{0}+\mathrm{c}_{1} \mathrm{t}+\mathrm{c}_{2} \mathrm{t}^{2}}{1+\mathrm{d}_{1} \mathrm{t}+\mathrm{d}_{2} \mathrm{t}^{2}+\mathrm{d}_{\mathrm{g}} \mathrm{t}^{3}}\right)
$$

Where,

$$
t=\sqrt{\ln \left[\frac{1}{(\mathrm{H}(\mathrm{x}))^{2}}\right]}
$$

For higher range of cumulative probability (i.e., $0.5<\mathrm{H}$ $(\mathrm{x})<1)$

$\mathrm{Z}=\mathrm{SPI}=+\left(\mathrm{t}-\frac{\mathrm{c}_{0}+\mathrm{c}_{1} \mathrm{t}+\mathrm{c}_{2} \mathrm{t}^{2}}{1+\mathrm{d}_{1} \mathrm{t}+\mathrm{d}_{2} \mathrm{t}^{2}+\mathrm{d}_{\mathrm{g}} \mathrm{t}^{\mathrm{s}}}\right)$

Where,

$$
t=\sqrt{\ln \left[\frac{1}{(1-H(x))^{2}}\right]}
$$

Here the values of the remaining coefficient are taken as follows:

$$
\begin{array}{lll}
\mathrm{c}_{0}=2.515517 & \mathrm{c}_{1}=0.802853 & \mathrm{c}_{2}=0.010328 \\
\mathrm{~d}_{1}=1.432788 & \mathrm{~d}_{2}=0.189269 & \mathrm{~d}_{3}=0.001308
\end{array}
$$

Analysis of drought occurrences: Drought occurrences in Manjalar sub basin have been investigated based on percentage of occurrence of drought events for each drought category at 3,6 and 12-month time scales. The aim here was to identify areas vulnerable to drought based on their occurrence frequencies. Percentage of drought occurrence was calculated by taking the ratio of number drought events in month to the number of total months over the study period (Edossa et al., 2010).

\section{RESULTS AND DISCUSSION}

Monthly distribution of drought: Monthly distributing of drought the results of monthly distribution of percentage of occurrence of drought at 3, 6 and 12- 
month time scale in the Manjalar sub basin is presented in Table 2. From the table it can be observed that the basin experienced frequent droughts for all months of the year. Monthly drought analysis for 30 year period, around 167, 172 and 176 number of months occurred drought at 3, 6 and 12 month time scale respectively. The highest percentage of occurrence of drought was observed in the month of July (15.3) followed by May (14.5), February and March at 3 month time scale. The percentage of occurrence of drought categories was computed as 69.77 per cent for mild drought, 14.19 per cent for moderate drought, 6.97 per cent for severe drought and 9.06 per cent for extreme drought at 3 month time scale (Table 2).

In 6 month time scale, the highest percentage of occurrence of drought was observed in the month of May (15.4) and the lowest drought occurrence was in March (13.7). The percentage of occurrence of drought categories was computed as $69.40,16.34,8.63$ and 5.63 per cent for mild drought, moderate drought, severe drought and extreme drought respectively. For the 12 month time scale, the highest percentage of occurrence of drought was observed in the month of August (15.6) followed by September, October and November. The percentage of occurrence of drought categories was computed as $66.41,17.4,11.34$ and 4.77 per cent for mild drought, moderate drought, severe drought and extreme drought respectively. The results show that mild droughts occur most frequently and extreme droughts occur least frequently.

Spatial and Temporal variation of drought: Lowest SPI values for three different time scales namely 3 months, 6 months and 12 months for the 12 rainguage stations during 1982-2012 are presented in Fig 2 and Table 3. Results show that the Vaigai dam received maximum SPI value (-4.04) is for 6 months timescale in the year 1985. For 3 month time scale, the maximum SPI value (-3.96) was found at Bodinayakanur in the year of 2006 followed by Cholavandhan in the year of 1997 and Vaigai dam (1985). The lowest SPI value $(-2.52)$ was found in Vaigai dam in the year of 1983 and 1992. For 6 month time scale, maximum SPI value was found in Vaigai dam, Nilakottai, Peranai and Cholavandhan and the values are $-4.04,-3.69,-3.67$ and -3.67 . The worst drought has been occurred in the year of 1985 and 2004. For 12 months time scale, the maximum SPI value was found in 2004 and the values are $-3.39,-3.33$ for Peranai and Cholavandhan station. It indicted that the amount of rainfall is very low (SPI predicts the value based on precipitation) and it might induce severe drought in that region. This findings harmony with Sigdel and Ikeda (2010) they found that, the severity of the drought is mainly due to low rainfall, high temperature, high wind and low relative humidity.

Drought occurrences: Spatial variation of percentage of drought occurrences for 3, 6 and 12 month time scales is presented in the Fig. 3. Percentage of occur- rence of drought is more in the south eastern parts and it decreases towards northern direction. It is noted that occurrence of drought at mountainous region is much lower than that the plain. Due to undulation nature of the study area, uneven distribution of rainfall and increased evaporation has increased the percentage of occurrence of drought in the Manjalar sub- basin. For 3 month time scale, the worst drought was occurred most of the study area except in western region. . In general, as the Sub-basin is bordered by hills except the north-east opening of the valley portion, it receives the highest rainfall in the northern and southern boundary of the study area. In contrast, the interior part receives relatively very low amount of rainfall as the area lies in the rain-shadow region of the valley. So the severe drought occurrence was recorded in South Eastern portion of the study area. For 6 and 12 month time scale, the most intense quantity was observed more in the lower and middle part of the basin than in the upper part basin. Some patches of most intensive extreme droughts were observed in the south-eastern parts.

Table 4 shows drought occurrences of Manjalar subbasin over the study area. From the table it was noticed that the mild drought was occurred frequently (around $32 \%$ ) than the extreme drought (around 2.5\%). As a result, in the 3, 6 and 12 month time scale, droughts will have greater severity in the south eastern parts in comparison to the other parts of the basin. Finally, the consequence of meteorological drought associated with hydrological drought has significant impacts on water resources of the basin. As the percentage of occurrence of drought in the North- eastern mountainous region is high, it eventually affects the available water storage of the reservoirs of Manjalar and Vaigai dam. This leads to decrease the surface water supply to the Theni, Dindigul and Madurai districts which have negative effect on agricultural activities as well as groundwater recharge. Tayeb et al. (2013) found that, the occurrence of severe drought due to higher intensity of rainfall, higher evapo-transpiration, less amount of ground water contribution, soil type and cropping pattern of that area.

\section{Conclusion}

This study was focused on analyzing temporal and spatial characteristics of droughts in the Manjalar sub basin using the SPI as an indicator of drought severity. GIS helps to generate drought severity maps for the different time scales. The temporal drought analysis of the SPI indicates that mild, moderate, severe and extreme droughts are quite frequent and suggest that the basin suffered severe drought during the year of 1985 , 2004 and 2006. These prolonged and persistent droughts seriously affected domestic water supply and agricultural irrigation. The results of spatial characteristics of drought showed that the central and south eastern parts of the basin have more potential sensitiv- 
ity to the droughts in comparison with the other areas of the basin based on drought severity. Droughts are more prevalent in south eastern areas of the basin in terms of percentage of occurrence of drought. The identification and characterization of droughts in the Manjalar sub basin will be useful for the development of a drought preparedness plan in the region so as to ensure sustainable water resource planning within the basin.

\section{REFERENCES}

Bhuiyan, C. (2004). Various Drought Indices for Monitoring Drought Condition in Aravalli Terrain of India, Proceedings of the XXth ISPRS Congress, Istanbul, Turkey, 12-23.

Edossa, D.C., Babel, M.S. and Gupta, A.D. (2010). Drought analysis in the Awash River Basin, Ethiopia. Water Resource. Management. 24: 1441-1460.

Edwards, D.C. and McKee, T.B. (1997). Characteristics of $20^{\text {th }}$ Century Drought in the United States at Multiple Timescales. Colorado State University: Fort Collins. Climatology Report No. 97-2.

Gibbs, W.J., Maher J.V. (1967). Rainfall Deciles as Drought Indicators, Bureau of Meteorology bulletin No. 48. Commonwealth of Australia: Melbourne; 29.

Gupta, A.K., Tyagi, P. and Sehgal, V.K. (2011). Drought disaster challenges and mitigation in India: strategic appraisal. Current Science. 100: 1795-1806.

Hughes, B.L. and Saunders, M.A. (2002). A drought climatology for Europe. International Journal Climatology. 22: $1571-1592$.

McKee, T.B., Doesken, N.J., Kleist, J. (1993). The relationship of drought frequency and duration to time scales. In Proceeding of the $8^{\text {th }}$ Conference on Applied Climatology, American meteorological society: Boston, 179-
184.

Mishra, A.K. and Desai, V.R. (2005). Spatial and temporal drought analysis in the Kansabati river basin, India. International Journal of River Basin Management. 3: $31-41$.

Moradi, H.R., Rajabi, M. and Faragzadeh, M. (2011). Investigation of meteorological drought characteristics in Fars province, Iran. Catena. 84: 35-46.

Palmer, W.C. (1965). Meteorological Drought, Research Paper No. 45. U.S. Department of Commerce Weather Bureau: Washington, DC.

Pradhan, S., Sehgal, V.K., Das, D.K. and Singh, R. (2011). Analysis of meteorological drought at New Delhi using SPI. Journal of Agro meteorology. 13: 68-71.

Shafer, B.A., Dezman, L.E. (1982). Development of a Surface Water Supply Index (SWSI) to assess the severity of drought conditions in snowpack runoff areas. Proceedings of the Western Snow Conference. Colorado State University: Fort Collins, CO; 164-175.

Sigdel, M. and Ikeda, M. (2010). Spatial and Temporal Analysis of Drought in Nepal using Standardized Precipitation Index and its Relationship with Climate Indices. J of Hydrology and Meteorology, Vol. 7, No. 1.5974.

Szalai, S., Szinell, C. and Zoboki, J. (2000). Drought monitoring in Hungary. In: Early Warning Systems for Drought Preparedness and Drought Management, WMO, Geneva, pp.161-176.

Tayeb Raziei., Isabella Bordi., Luis Santos Pereira (2013). Regional Drought Modes in Iran Using the SPI: The Effect of Time Scale and Spatial Resolution. Water Resource Management. 27: 1661-1674.

Wu,H., Hayes, M.J., Welss A., Hu,Q. (2001). An evaluation the standardized precipitation index, the china-z index and the statistical z-score. International Journal of Climatology. 21: 745-758. 